\title{
GEO-EYE
}

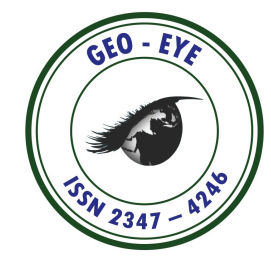

RESEARCH ARTICLE

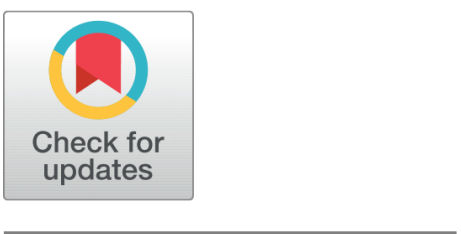

OPEN ACCESS

Received: 02.02.2020

Accepted: 18.05 .2020

Published: 28.05 .2020

Citation: Akhil S, Jayapal G. (2020). LANDSCAPE MODIFICATION IN KANNUR COAST, KERALA. Geo-Eye. 9(1): 26-32. https://doi.org/ 10.53989/bu.ge.v9i1.6

Funding: None

Competing Interests: None

Copyright: (c) 2020 Akhil \& Jayapal. This is an open access article distributed under the terms of the Creative Commons Attribution License, which permits unrestricted use, distribution, and reproduction in any medium, provided the original author and source are credited.

Published By Bangalore University, Bengaluru, Karnataka

ISSN

Print: 2347-4246

Electronic: XXXX-XXXX

\section{LANDSCAPE MODIFICATION IN KANNUR COAST, KERALA}

\author{
S Akhil', G Jayapal ${ }^{2}$ \\ 1 Research Scholar, Department of Geography, Kannur University, Swami Anandatheertha \\ Campus, Payyanur, India \\ 2 Assistant Professor, Department of Geography, Kannur University, Swami Anandatheertha \\ Campus, Payyanur, India
}

\section{Abstract}

The term landscape is used in many different contexts with numerous different definitions. In most disciplines it has a clear spatial dimension based on natural as well as cultural. From an ecological point of view, a landscape may function as a scale measure relative to the movement of different organisms, usually a large area including components like heterogeneity and habitat mosaics. In social science and humanities, landscape is commonly conceived as a holistic dimension, a continuum without limits, where physical elements, socio-economical qualities and institutional components are included together with immaterial aspects such as value systems, tradition and knowledge. The degree of Naturalness can be used as a criteria for identifying and delineating the landscape anywhere since the all regions in the world are somewhere in the range from a natural to cultural landscape transformation.

Keywords: Landscape; Naturalness; NDVI; Population Density

\section{Introduction}

The word landscape has complex and multiple meanings according to the perception and background of the users. Also, the meaning of the term changes with changing environmental conditions (Akhil and Jayapal, 2019). Landscape does not only refer to a complex phenomenon that can be described and analysed using objective scientific methods; it also refers to a subjective observation and experience and thus has a perceptive, aesthetical, artistic and existential meaning as well (Cosgrove and Daniels, 1988). A number of methods were also proposed to classify various land forms into natural and cultural landscape. Since the mid-20th century, the term landscape got interpreted in a diverse way by different scholars in different contexts, where it acquired to have a multidimensional quality (Tress et al., 2006). Meinig (1976) has attempted to summate ten variations of the landscape dimension and its interpretations as: nature, habitat, artifact, system, places, problem, wealth, ideology, history and aesthetic, and prescribe to be responsive of the above, as a step towards effective communication.

The classification of landscapes is complicated by the fact that it involves both human perception and physical reality, while many of the science classifications tend to be based on just the physical. 
It is critical that a landscape classification be developed so that landscape research can advance our understanding of the nature of landscapes and ascertain the values associated with different landscapes. Landscape perception depends not only on these physical landscape components, which may be extremely diverse, interrelated and complex, but also on the values, past experience and social-cultural conditioning of the observers.

Naturalness is one of those factors, like degree of uniqueness, diversity, ecological integrity, opportunity for sustainable development and scientific value; considered by the UNEP Caribbean Environment Programme, 1996 for determining the significance of the natural area and stated that in developing protected areas it is generally possible to identify three different areas like:

- Areas with high degree of naturalness, where human impacts are not detected or have a very weak manifestation, allowing for a substantial amount of primary vegetation.

- Areas with a medium degree of naturalness, where natural landscapes and features prevail, but with locally modified places which could recover through effective environmental management.

- Areas in which a high degree of modification has occurred however, there are remaining isolated and scattered natural sites with the special ecological or historical/cultural interest. (UNEP Caribbean Environment Programme, 1996)

\section{Study Area}

Kannur district have nine coastal panchayats which are New Mahe, Dharmadom, Muzhappilangad, Edakkad, Pallikunnu, Azhikode, Mattool, Madayi and Ramanthali and Thalassery Municipality and Kannur Corporation. The density of population in these panchayats, the activities by the people and the stress exerted by these on the area namely infrastructure and tourism may cause the alteration of landforms in a rapid rate than its natural change over time.

\section{Materials and Methods}

The Landscape Classification based on the principle of degree of naturalness adopted by the New Zealand government, which scored from 1 (Natural) to 5 (Unnatural) has been modified for better understanding of the terminologies and applicability in the case of Kannur coast, Kerala. The naturalness score can be used for identifying natural as well as cultural landscapes. For analysing the change in naturalness, NDVI has been used for the period of 1911-2011. The population density and growth rate of the period is also analysed to understand the impact of demography on the changing landscapes.

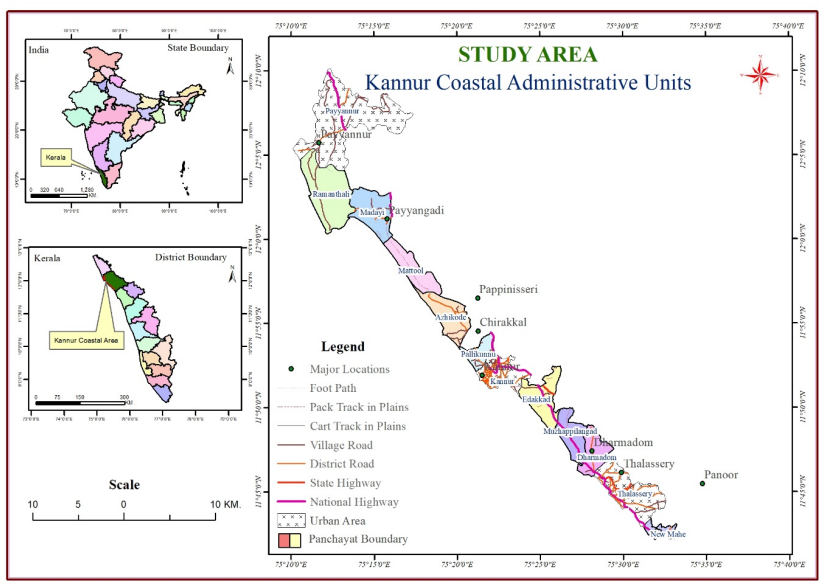

\section{Analysis and Results}

For identifying the landscape, a criteria needs to be defined. Many works have used various criteria for landscape identification and delineation. New Zealand government classified the landscape of the country on the basis of land use components, water components, infrastructure component and naturalness.

The naturalness criteria used by Babryn (2006) for the New Zealand Landscape Classification has been modified for this study. The 5 rating scale from Natural to Unnatural, based on the degree of decreasing naturalness. The terms for the classes of natural, semi-natural and unnatural are taken as such, with little modifications in the description while 'natural with an unnatural wider context' has been renamed as 'Subnatural' and 'Unnatural with a natural wider context' has been renamed as 'Subter-natural'.

\section{Natural}

Oxford Dictionary, 2003 described the term 'natural' as "in accordance with the nature of, or circumstances surrounding, someone or something". All natural vegetation (forest, mangroves and wetlands), landforms and water components were assumed to be natural. Natural landscape units includes Open and Fairy Jungle, Mangroves (inhabited and protected), Wetlands (protected and inhabited), Waste lands (barren lands and rocky outcrops), water bodies (river mouths, lagoons and other permanent water bodies) and uninhabited islands.

Though 'natural' is described as the absence of human modification, it is accepted that the chance of having an area with no human interference is almost absent, and so the percentage of naturalness in 'natural' is assigned as $80-100 \%$.

\section{Sub natural}

The word sub-natural means 'not quite natural'. Oxford Dictionary, 2003 described the term 'sub' as 'at, to or 


\begin{tabular}{|c|c|c|}
\hline $\begin{array}{l}\text { Naturalness } \\
\text { Score }\end{array}$ & Name & Description \\
\hline 1 & Natural & $\begin{array}{l}\text { Absence of human } \\
\text { modification }\end{array}$ \\
\hline 2 & Sub Natural & $\begin{array}{l}\text { Natural component } \\
\text { but not completely } \\
\text { natural. The com- } \\
\text { ponent with natural } \\
\text { character but subjected } \\
\text { to some modifications } \\
\text { determined from the } \\
\text { dominant land cover } \\
\text { component. }\end{array}$ \\
\hline 3 & Semi Natural & $\begin{array}{l}\text { Agricultural land cover } \\
\text { that has an absence of } \\
\text { major infrastructure. }\end{array}$ \\
\hline 4 & Subter-natural & $\begin{array}{l}\text { A little naturalness. } \\
\text { A natural component } \\
\text { within a wider cultural } \\
\text { area, such as an urban } \\
\text { area or agriculture } \\
\text { landscape. }\end{array}$ \\
\hline 5 & Unnatural & $\begin{array}{l}\text { Urban land use, } \\
\text { densely settled areas } \\
\text { and major infrastruc- } \\
\text { tural areas }\end{array}$ \\
\hline
\end{tabular}

from a lower level or position, somewhat nearly, more or less denoting subsequent or secondary action of the same kind". Siddhartha and Mukherjee (2000) describes 'sub' as "indicating a condition that is slightly outside the lower limit of a given condition". This class includes those component with natural character but subjected to some modifications determined from the dominant land cover component. The character of the component is still natural to the major extend but it shows the sign of human interferences. They include coastal plain, alluvial plain, plateau/hill and islands which have higher natural character than human. Sub-natural class has a given $60-80 \%$ naturalness.

\section{Semi-natural}

'Semi' means "partly in some degree or particular". Seminatural landscapes contain a substantial number of elements and features significantly modified by human activities. It is not something to be clearly defined or scrutinised, but it refers to landscapes which have modified by human activity over long periods of time (Maija et al, 2013). The cosmos dictionary of Geography describes 'semi-natural' vegetation as "a vegetation type that owe some characteristics to the natural conditions of soil and climate but that has been modified by human activity, particularly farming." Thus a semi natural landscapes unit is an area which is partly natural and partly cultivated. Thus it can include all the agricultural land, kaippad lands (prominent agricultural type in the region) and pisciculture sites. Regions with 40-60\% naturalness has been included in this class, which means that it can have almost $50 \%$ of the human inference as well.

\section{Subter-natural}

Collins Dictionary describes the word 'subter' as "below/ less than" and according to the Educalingo Online Dictionary 'subter-natural' means "falling below what is accepted as natural or something less than natural". Thus it can be said that subter natural landscape units includes those unnatural components that are culturally formed but still with natural influences.

Subter- natural is just opposite to sub-natural, where the component is almost a cultural one with large human modifications, but still have some naturalness in it. It includes settlements, tourism spots, harbours and parks with some physical element in it. Subter natural class accounts $20-40 \%$ of naturalness or high human interference.

\section{Unnatural}

The term unnatural here does not "abnormal", it means something that can be explained as "with no natural presence" or "not existing in nature or artificial". The MerriamWebster dictionary defined unnatural as "not being in accordance with nature or consistent with a normal course of events". Unnatural or cultural units are the product of human activity which do not have any kind of natural involvement at the moment. Unnatural are those with only a few naturalness below $20 \%$ which means the region is almost absent or high alteration of naturalness or vegetation or water body. Unnatural/cultural elements includes those which are completely Urban areas likes census towns and municipalities and built ups like industrial areas and Other Dense Settlements (Alluvial plain, Fishing villages, Hilly areas).

\section{NDVI Analysis}

The normalized difference vegetation index (NDVI) is one of the most widely used vegetation indexes and its utility in satellite assessment and monitoring of global vegetation cover has een well demonstrated over the past two decades. (Jiang et al, 2006). NDVI values range from +1.0 to -1.0 . Areas of barren rock, sand, or snow usually show very low NDVI values (for example, 0.1 or less). Sparse vegetation such as shrubs and grasslands or senescing crops may result in moderate NDVI values (approximately 0.2 to 0.5 ). High NDVI values (approximately 0.6 to 0.9 ) correspond to dense vegetation such as that found in temperate and tropical forests or crops at their peak growth stage (USGS, 2018). When you have negative values, it's highly likely that it's water. On the other hand, if you have a NDVI value close to +1 , there's a 
high possibility that it is dense green leaves. But when NDVI is close to zero, there isn't green leaves and it could even be an urbanized area (GIS Geography, 2020).

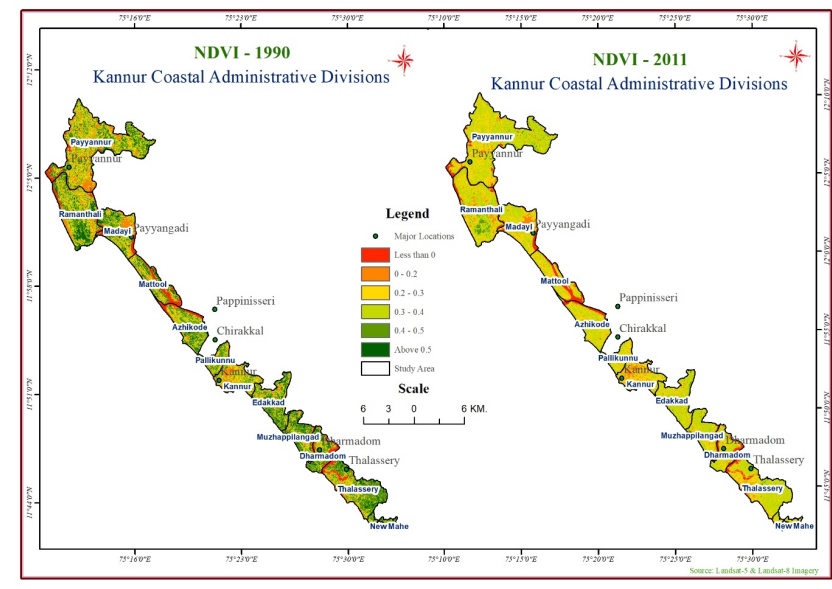

The NDVI has been classified into five groups from Very High Vegetation to No Vegetation. Very High Vegetation area includes thick and natural vegetation of forests, mangroves and wetlands and No Vegetation area can either be built ups, barren rocky area or even water bodies. So No Vegetation in NDVI does not necessarily mean built-ups/ construction only, it may be rocky hills or water bodies as well. In case of coastal administrative units exposed barren rocky hills could not be identified. So No Vegetation can be either built ups/construction/roads or water bodies.

Incorporating the NDVI classes with the landscape classes, it can be viewed Very High Vegetation area as Natural Landscape and No Vegetation area as Cultural or Unnatural Landscape. Likewise High Vegetation area can be considered sub-natural landscape and Moderate Vegetation area as Semi-Natural Landscape. Though semi-natural landscapes are considered as agricultural landscapes, NDVI does not categorize agricultural fields or forest area, it just analyse the vegetation. The Low Vegetation area in NDVI class can be considered as Subter-natural landscape. So the NDVI classification can be compared and interpolated into the landscape classification based on Naturalness.

\section{1}

In 1991, out of the 221 sq. km study area, 18.04 sq.km (8.18\%) was Very High Vegetation area; that is mangroves and wetlands (could not find any forest cover). High Vegetation area was having the highest percentage of $33.78 \%$ (74.5 sq.km) followed by Moderate Vegetation area (24.28\%), Low Vegetation area, Very Low Vegetation area and No Vegetation area which had the lowest percent of area with 16.91 sq.km, that is only $7.66 \%$ of the total study area. This means it includes the area of water bodies also. If the percentage of water bodies is excluded then the total built up area or as it can say the Unnatural/Cultural Landscape in 1991 was very less.

Analysing the NDVI of 1991 we can see Very High Vegetation in north eastern parts of Payyanur, southern part of Ramanthali, northern parts of Madayi, parts of Edakkad, Muzhappilangad, coastal stretch of Dharmadom, eastern parts of Thalassery and New Mahe. High Vegetation is seen in patches in almost all administrative units except Azhikode, Pallikkunnu and Kannur. NDVI index of Moderate vegetation (0.2-0.3) is seen in every administrative units of the study area. This class have the second highest area (54 sq.km) under cover in 1900. Low vegetation comes third in area with $13.88 \%$. It is also evenly spread in patches in the entire study area.

Very low Vegetation is seen in the coastal stretch or Ramanthali, hilly region of Madayi, Payyanur, Kannur town, eastern part of Edakkad, and Thalassery town. These region could be either a hilly tract with very less vegetation or a town with less vegetation. Both the low vegetation and very low vegetation classes were combined together it would become the highest classes in area. By doing so the classes can be considered as the Subter-natural landscape class having less vegetation and high human influence. No Vegetation is the lowest percentage class in 1991 with only $7.66 \%$ of the area which also include water bodies with the constructions and road networks. Reducing the percentage of water bodies from the $7.66 \%$, then the total built-up including roads is even less that the Very High Vegetation class. So it can be said that in 1991, though the study area had three municipalities and five census towns, the area with complete human influence was very less. Though we cannot expect a completely natural landscape without any human interference in 1900s especially in coastal low lands, the area where natural vegetation prevailed that time was higher that the unnatural/ cultural landscape.

\begin{tabular}{lllll}
\hline Year & \multicolumn{2}{c}{$\mathbf{1 9 9 0}$} & \multicolumn{2}{c}{$\mathbf{2 0 1 1}$} \\
NDVI & $\begin{array}{l}\text { Area in } \\
\mathbf{K m}^{2}\end{array}$ & $\begin{array}{l}\text { Area } \\
\text { in \% }\end{array}$ & $\begin{array}{l}\text { Area in } \\
\mathbf{K m}^{2}\end{array}$ & $\begin{array}{l}\text { Area } \\
\text { in \% }\end{array}$ \\
\hline $\begin{array}{l}\text { Very Low } \\
\text { Vegetation }\end{array}$ & 26.95 & 12.22 & 19.17 & 8.67 \\
$\begin{array}{l}\text { Low Vegetation } \\
\text { Moderate }\end{array}$ & 30.6 & 13.88 & 67.41 & 30.50 \\
$\begin{array}{l}\text { Vegetation } \\
\text { High }\end{array}$ & 54 & 24.28 & 115.62 & 52.32 \\
$\begin{array}{l}\text { Vegetation } \\
\begin{array}{l}\text { Very High } \\
\text { Vegetation }\end{array}\end{array}$ & 74.5 & 33.78 & 4.05 & 1.83 \\
$\begin{array}{l}\text { No Vegetation } \\
\text { Total }\end{array}$ & 16.04 & 8.18 & 2.31 & 1.05 \\
\hline & $\mathbf{2 2 1}$ & 7.66 & 12.44 & 5.63 \\
\hline
\end{tabular}




\section{1-2011}

In 2011 the Moderate Vegetation class is the having 115.62 sq. $\mathrm{km}$ that is $52.32 \%$ occupies majority of the total study area, which is followed by Low Vegetation area (67.41 sq. $\mathrm{km})$. Comparing with the NDVI of 1991 the Very High $(18.18 \%$ in 1991 to $1.05 \%$ in 2011 ) and High vegetation $(33.78 \%$ in 1991 to $1.83 \%$ in 2011) areas has been decreased drastically within 20 years. In 1991 both these categories together made an area of 92.54 sq.km which is $41.96 \%$ of the study area whereas in 2011 it has been reduced to just 6.36 sq.km (2.88\%) of the total area shows the vast conversion of vegetation area in the meantime, which is a serious problem of concern. The decrease in the Very High and High Vegetation area and the sharp increase in Moderate Vegetation to over 28\% area shows sign of the conversion of vegetation land for agriculture or housing or other allied activities.

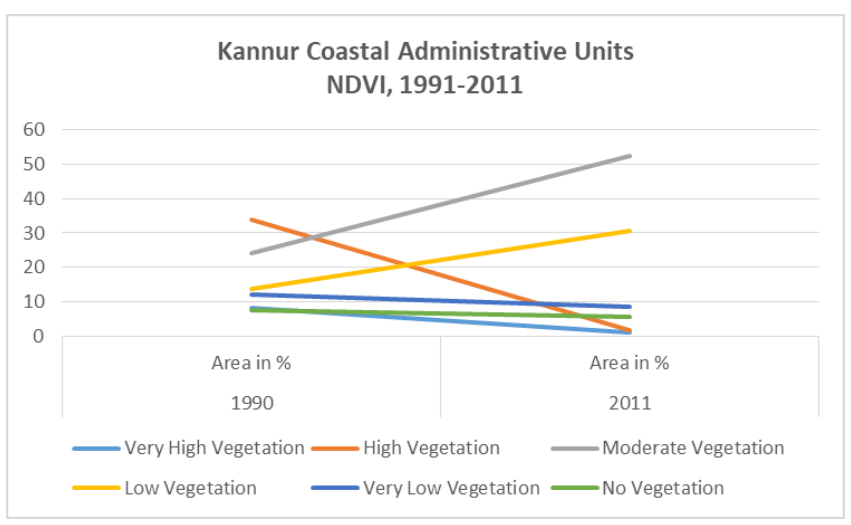

Form the graph it can be understood the rate at which each vegetation class has changed. Both the extremes classes of Very High Vegetation and No Vegetation has under 10\% of the total study area in 1991. Very Low Vegetation has also been decreased from $12.22 \%$ in 1991 to $8.67 \%$ in 2011 , which indicates the conversion of these areas to built-ups or those areas near the built-up been developed as a part of town due to development and expansion in due course of time.

The place where the Very High Vegetation is identified from the NDVI map is in Ramanthali panchayat. The place is now under the custody of Ezhimala Naval Academy which has stated operating since 2005. The other places with Very High Vegetation are actually spots in Edakkad, Thalassery and Muzhappilangad. High Vegetation regions were also highly decreased such that small spots can only be identified in the western parts of Payyanur, Ramanthali, Madayi, Edakkad and Thalassery.

Moderate Vegetation has been the most dominant class in 2011 which us seen throughout the region except the city regions of Kannur and Thalassery. From the maps it is evident that the Very High and High Vegetation areas in 1991 has been converted as Moderate Vegetation areas but we cannot conclude these moderate vegetation is completely agricultural areas since there is no evidence to prove a huge uprising of the people towards agricultural activities in the meantime. Some of these panchayats has reached almost zero agriculture between 1911 and 2011, which also suggests the converted land is not for agriculture completely.

Low Vegetation class has increased more than double with the 20 years span, which also makes some concern over the converted area. Since there is a decrease in Very Low Vegetation areas (12.22\% in 1991 to $8.67 \%$ in 2011) and No Vegetation (7.66\% in 1991 to $5.60 \%$ in 2011), those increased area of $16.62 \%$ in the Low Vegetation class can be a sign of reverse trend towards 'naturalness'. Low Vegetation is seen widely throughout the study area whereas Very Low Vegetation is seen in the city regions of Kannur and Thalassery, spots of Edakkad, Pallikkunnu, Muzhappilangad, Payyanur and other panchayats especially along the National Highway. The most prominent areas are the Madayi para, the barren laterite hill in Madayi panchayat and the Kallettinkadavu region in Ramanthali where laterite mining is prominent. No vegetation is seen as lines not as pockets in the maps showing those line features are water bodies and not an urban area.

The possibility of rocky hills removed or vegetated can be seriously considered. There are little chance of hills being vegetated, than being removed for quarries and residential/commercial purposes. The clay mining at Madayi para is an example of that. Barren tracks of Payyanur, Ramanthali, Madayi and Edakkad have found decreased.

No Vegetation is something which is practically difficult to find in Kerala for the time being but NDVI suggests NO Vegetation areas would be mostly road, river/water bodies and barren rocks. The no vegetation class has also decreased from $7.66 \%$ to $5.63 \%$. This change/decrease of over $2 \%$ or 4.47 sq. $\mathrm{km}$ area need to be analysed carefully. Though the major areas showing No Vegetation in the NDVI map are built ups, roads and water bodies, the decreased instead of increase in areas is something to look at.

When there is an increase in No Vegetation area it suggests four possibilities: (1) the built ups/construction has increased, (2) the road network has increased, (3) the rocky hills were not disturbed, and (4) the water bodies have increased or left untouched. But the decrease in No Vegetation area can suggests: (1) Vegetation has increased, (2) the built ups have decreased/ settlements have shifted, (3) road network is decreased, (4) rocky hills were removed or vegetated, and (5) water bodies have decreased.

Considering the case of the coastal administrative units of Kannur district, it is very difficult to say the built up and road network has decreased. It is evident that the road and built up has increased in the study area both maps and also in statistically. Removal and vegetation of rocky hills would be another reason but the hilly tracks in the study area has been 
recognised as Low Vegetation areas in the NDVI.

Increase in vegetation would be another reason, but is not acceptable as such as the Low Vegetation areas have also been declining in the meantime. Except Moderate Vegetation, all other vegetation classes have a huge decrease in vegetation. Though stated before Moderate Vegetation may be the agricultural lands and the decrease of land from Very High Vegetation and High Vegetation may be the reason of keeping this Moderate Vegetation class somewhat stable (a slight decrease of $3.95 \mathrm{sq} . \mathrm{km}$ ) for the last 30 years. This has been substantiated by the increase in Low Vegetation area (huge increase of almost 90 sq.km) and Very Low Vegetation area where the area might have converted for agriculture or residential/commercial purposes. So, in general the trend is moving in a direction away from 'Naturalness'.

So the most possible reason for decrease in No Vegetation area would be decrease in the water body areas. It is evident that the river channels have been encroached for the past years. River mouth in Mattool-Azhikode border and the channel of Ancharakandy River on the DharmadomThalassery border have found shrinked. In the Mattool panchayat the entire river channel is being disturbed. So it can be show from the NDVI map and statistics that the decrease in No Vegetation area can be due to the decrease in water body area in the region.

\section{Population Aspects}

Growth rate, Density of population, from 1991 to 2011, of the coastal administrative units of Kannur district have analysed. Growth rate from 1991 to 2011, show a range of population growth from $26 \%$ to $-12 \%$. Muzhappilangad panchayat shows the highest growth rate (26\%) followed by Edakkad panchayat (22.6\%). Ramanthali panchayat (2.05\%) and Dharmadon panchayat (15.3\%). Kannur municipality is having the lowest growth rate of $(-12 \%)$ followed by Thalassery municipality (-10.6\%), New Mahe (2.4\%) and Madayi panchayat (7.1\%). Kannur and Thalassery are the only places with negative growth rate.

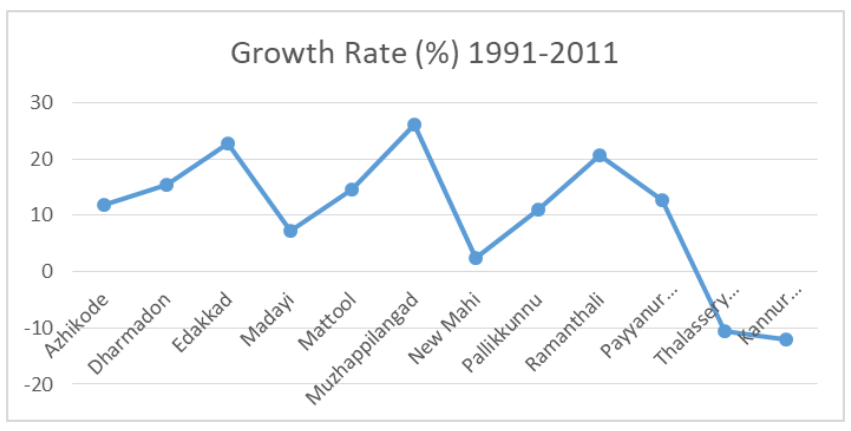

There are various reasons for population decline like Biological factors (birth control, infertility, aging etc.), Eco- nomic factors (Prolonged marriage and delivery due to carrier opportunity, lack of income, low standard of living, migration due to job opportunities etc.), Political and Social factors (disasters, violence, catastrophes, migration etc.).

Migration for economic purposes usually occurs from rural to urban areas. But when people start migrate from urban to rural it can be due to social and political reasons like difficulties in living and get settled in an urban area and the low economic income to sustain in the region.

Analysing the increase of households from 1991-2011, the highest increase is recorded in Payyanur municipality with 6036 houses followed by Thalassery municipality (4509 houses), Azhikode (3658 houses) and Edakkad (3478 houses). The lowest increase area recorded in New Mahe (1137 houses), Mattool (1456) and Kannur Municipality (1794).

As stated above the high land value and regulations would force the people to settle outside the city region. The effect of it can be witnessed in Azhikode, Edakkand and Pallikunu Panchayats. Though Thalssery has the second highest increase rate, the outflow of people can also be seen in Dharmadom panchayat. The decrease in total population in Kannur and Thalassery municipality from 1991-2011 can also due to this out migration. But this trend is not seen in Payyanur municipality region, because as compared with the total areas of Kannur (12.82 sq.km) and Thalassery (23.96 sq.km), Payyanur municipality (54.63 sq. $\mathrm{km}$ ) can accommodate more people with one of the lowest density (1319 people/sq.km) in the study area.

Analysing the density from 1991-2011, then trend seems to normal except Kannur and Thalassey municipalities. Though Kannur has the highest density of population in 1991 and 2011, in the study area, with 5465 person/sq.km and 4806 person/sq. $\mathrm{km}$ respectively, there is a decrease of 759 person/sq. $\mathrm{km}$ in the period. Except these two administrative units all other place show an increase in the density of population. Pallikunnu is having the second highest density in 2011 with 1032 people/sq.km, followed by Thalassery, Muzhappilangad (3298), and New Mahe (3210).

In 1991 Kannur was followed by Thalassery (4323), Pallikkunnu (3632), New Mahe (3133), Azhikode (2641), Muzhappilangad (2626) and Dharmadom (2505). The lowest density was shown by Ramanthali panchayat with 711 and 857 person/sq.km in 1991 and 2011 respectively.

Decrease in density in Kannur and Thalassery could be the result of people settling outside the city region. This can directly alter the land use of the surrounding places. People while shifting from city to outskirts and settle in surrounding regions they try to modify the area. Since the regulations in panchayats are not as strict as the municipalities, they try to alter the area. The rules and regulations also force residential flats and villas to move outside the city regions, but not very far away from the city. As a result of these, more stress will be experienced in panchayats nearby the city like Pallikunnu 
and Edakkad panchayats un case of Kannur municipality and Dharmadom and New Mahe panchayats in case of Thalassery municipality.

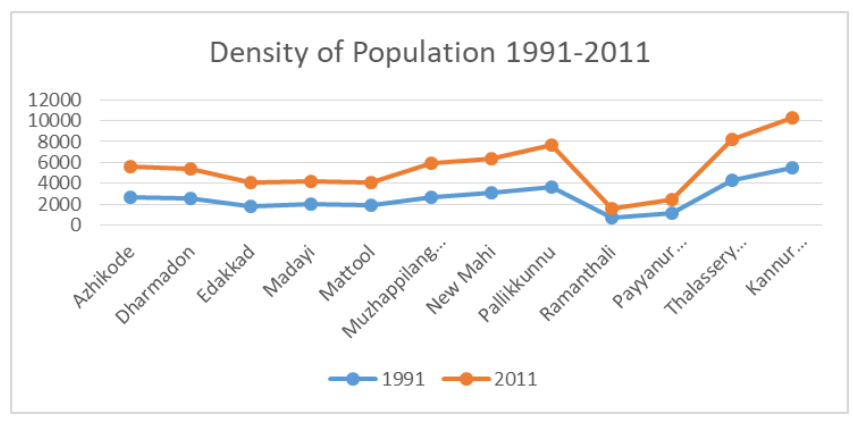

Many people, especially the middle income group are settling in peri-urban areas because they can find better quality housing with more living area as the cost of getting a property there won't be as high as in the city. Out migration from the city centre to the peri-urban areas may also due to the demand for a greener, more attractive and family friendly environment. It also makes the people feel that they can afford housing in the outskirts with their needs.

The change in trend from 1991-2011 suggests that, like formerly mentioned, the decrease in density of Kannur and Thalassery may be due to the out migration of people to neighbouring panchayats like Pallikunnu, Azhikode, Edakkad, Dharmadom and Muzhappilangad. These units aren't the only places people could have migrated and thus the actual number of people missing from Kannur and Thalassery cannot be completely found in the study area itself. Even then it is clear that the decrease in growth rate, total population, number of households and density in Kannur and Thalassery municipalities could be the effect of out migration where people like to settle in commuter's zone with respect to these urban areas. The subsequent increase in the above said parameters in Pallikunnu, Azhikode, Edakkad, Muzhappilangad and Dharmadon panchayats points out on this conclusion.

\section{Findings and Conclusion}

Change in naturalness is normal in the urbanising society where people alter the landscape, but the trend in change of naturalness in the region suggests a sign of sudden increase in the area of No Vegetation in the near future. For example the High Vegetation class has decreased from almost 34\% in 1991 to almost $1.5 \%$ in 2011 , a shocking decrease of 70.45 sq.km in just 20 years. In 1991 Low and Very Low Vegetation had only $12-13 \%$ of the total area, which has changed drastically in 2011 itself (Very Low Vegetation slightly reduced almost $4 \%$ while Low Vegetation increased to more than $30 \%$ area. The Moderate Class showed a hike of almost $62 \mathrm{sq.km}$ in the time period.

The trends in population dynamics shows a sign of migration from urban centres to the neighbouring areas, which is the prime reason for the change of naturalness in these panchayats. This pattern would create pressure to the landscapes on the panchayats near Kannur and Thalassery. These city regions might have already been into the subter and unnatural landscape classes. This trend in migration and their resultant economic and household activities would force these above said panchayats to transfer from sub-natural or semi-natural landscapes to subter natural landscapes. But the number of households and density of population alone cannot be the deciding factors for landscape transformation. It is more influenced by the behaviour of people in terms of their activities performed. Anthropogenic activities largely alter the landscape of a region. Those activities may be economic or non-economical, but it can transform the land from an absolute natural landscape to an utter unnatural/cultural landscape in due course of time.

\section{References}

1) Meinig DW. The Interpretation of Ordinary Landscapes. Geographical Essays. New York. Oxford University Press. 1979.

2) Akhil S, Jayapal G. Landscape: A Geographical Review. International Journal of Applied Social Science. 2019;6(5):1166-1172.

3) Cosgrove D, Daniels S. The iconography of landscape: essays on the symbolic representation, design and use of past environments. Cambridge. Cambridge. Cambridge University Press. 1988.

4) Brabyn L. New Zealand Landscape Classification Version II: A Classification of Visual Landscape Character. 2006. 